\title{
The Alpha State Theory Internationalization as Means to the End of Globalization
}

\author{
Vardaan Shekhawat* \\ University of Delhi, Depart of Political Sciences
}

*Corresponding Author: Vardaan Shekhawat, University of Delhi, Depart of Political Sciences

\begin{abstract}
The third world's paradigm towards the widespread globalization in terms of policies brought forth as bi-products of the Bretton-woods sisters; The International Monetary Fund, The World Bank and the World Trade Organization remains largely in oblivion.

As a critical discourse analysis, in terms of Hebermas' Language Philosophy, the Third-world lacks a concrete theoretical principle or language to elucidate the exploitation and unjust facets that lead to globalization. These facets collectively make the prequel to globalization: Internationalization.
\end{abstract}

The understanding here is that profitability is not wrong, however, stripping off of language to express the exploitation as a result of that profitability is morally unjust.

Thus, this paper attempts to provide the language and theoretical apparatus to highlight third-world exploitation that remains hidden under the garb of globalization, using a distinctive concept of alpha state theory. It also attempts to understanding internationalization as a process that leads into globalization.

\section{INTRODUCTION}

Globalization is often associated with development, but to understand globalization in the wider context of development is the deliberative aspect. For, the image of globalization suddenly induces a feeling of better food, better clothing and better quality of life within third world states. For instance, coming in of brands such as McDonald's, Zara, etc. are all outcomes of a more liberalized and globalized state. But running parallelly to these MNCs and world-known brands, a situation of extreme poverty, extreme helplessness and agony exists.

With that as a pretext, some hyper-globalist scholars move forth with the presumption that economic growth and economic efficiency are not only necessary but also sufficient to bring forth an improvement in the living conditions of people.

However, this is not always rationally and economically correct, based upon the scheme of economic policy in action, economic growth may just increase disparities at large. Here the argument of the trickle- down effect of economic growth to the poorest sections of the society does not make sense because even though the trickle-down exists, it remains way too slow to see any tangible change, this has been the trend in most of the third world states.

The psychological justification here simply is, why would the rich want the poor to get richer and thereafter be a competition? This applied to the understanding between nation-states remains the same. Thus, well off states, via internationalization continue this regime of exploitative policies, even though at the surface some developing states experience economic growth.

Internationalization is usually associated with economic terms by the popular phrase of I18N denoting the process of developing products in such a way that they can be localized for languages and cultures easily. However, a more sophisticated definition comes from the journal of international business study,

"Internationalization of the firms or states is a process in which the they gradually increase their 
international involvement."

Internationalization, thus in the realms of public management and administration investigates increasing involvement of nation states in the international arena, thus highlighting the changes in policy patterns based on value judgments to manage externalities and the equilibrium between domestic and international spheres.

With such a phenomenal increase in international involvement and dependency of nation states on each other. It is of prime importance to see how ordinary citizens are affected by a change in public policy. For instance, at the time of the liberalization reforms in India, multiple small-scale domestic enterprises of handicrafts were adversely affected due to a high level of competition coming in from highly industrialized countries of the west, as a result of which consumers could receive similar goods for a highly reduced price. Whereas, Indian goods remained highly priced.

Thus, the analysis is not to provide a binary to the question of globalization being good or bad, but it is to understand the prequel to globalization; Internationalization. While also providing a language and theoretical stand-point to the third world perspective that has been the biggest victim of exploitative internationalization.

\section{Devising a Theoretical Perspective}

Set of ideas floating in an abstract manner is rationally illogical and yields no results, ideas until collaborated and joined together shall hold minimal relevance and purpose. Thus, to channelize a positive flow of ideas leading to conclusive results or collective action, theory becomes imperative. To maintain simplicity of analysis and understanding, recognizing a definitive meaning to theory becomes essential, thus within the framework of this paper theory shall stand as; A theory a set of interrelated concepts, definitions, and propositions that explains or predicts events or situations by specifying relations among variables, that may or may not be validated.

A theoretical perspective to any event, activity or process becomes essential to maintain its simplicity and open it to diverse interpretations. In case of marginalized and suppressed groups, theory becomes even more important to give a logical ideation to their standpoint and highlight the victim's perspective, by giving them a language of their own. Thus, creation of language begins with the creation of an ideological theory.

The beauty of theoretical perspectives in social sciences lies in its testability and validation. Theories vary in the extent to which they have been conceptually developed and empirically tested; however, "testability" is an important feature of a theory. Social science theories are better understood as models that work in a limited range of settings, rather than laws of science which hold and apply universally. ${ }^{2}$

Thus, in all facets of theory or theorization one commonality that remains is the desperate hunger to collectivize ideas towards a common goal.

Therefore, to build a theoretical perspective towards the advent of internationalization, what becomes imperative is to understand the nature and scope of the term itself. The following section talks of internationalization as a non-liberating but limiting factor unless taken up by the state itself on its own terms and conditions, or within a fair international structure of negotiations and bargaining.

It moves forth to highlight and provide the exploited third world with a language and theorization of its own, in terms of analyzing the working of an assumed alpha state.

\section{InTERNATIONALiZATION-As ThE MEANS TO AN END OF GLOBALIZATION}

The beauty of academia of humanities lies in the essence of interpretation and art, wherein nothing ends with just a black or a white, humanities elucidates the beauty of grey. Always leaving you with not a binary but a multiplicity of opinion and ideas over one single subject or topic.

\footnotetext{
${ }^{1}$ As per Jan Johanson and Jan Erik Vahlne ; journal of international business study, (THE INTERNATIONALIZATION PROCESS OF THE FIRM-A MODELOF KNOWLEDGEDEVELOPMENT AND INCREASING FOREIGN MARKET COMMITMENTS JAN JOHANSON* Center of International Business Studies University of Uppsala JANERIK VAHLNE* Institute of International Business Stockholm School of Economics)

${ }^{2}$ As Stephen Turner has noted in his chapter on "Theory Development,"
} 
Internationalization, in this aspect remains a topic that hinges upon an idea that stems from the multiple characters, phases and faces of globalization. Thus, to put in a nutshell internationalization may be the slow unfolding of globalization, highlighting the philosophical changes followed by which we see the economical and other aspects of ideological transformation as a result of wide-scale globalization.

Contemporary scholars write widely on the aspects, schemes and models of globalization but do not highlight the prequal to globalization, does globalization happen out of nowhere? what are the preconditions to globalization? And multiple other questions that seek to understand the phase between globalization and a closed, protectionist society.

Globalization is forcing the states to restructure their national economies, to interconnect with the global economic flows, making them also more vulnerable to the developments in the global economy and to the oscillations of the flows in the world economy. "The new ways of economic management of the states, the various competitions between the state's competences, plus a number of specific local factors (such as secessionist trends) facilitate a fragmentation of the society. The nation- state ceases to be an effective economic manager" ${ }^{3}$.

"Although the states continue to be the main actors in international business they already suffer losses of sovereignty, functions, power"4.

The phase of philosophical transformation within the public administration and the executive and the

legislators, the force which sweetly converts the idea of protecting one's own economy, culture and ideas to opening oneself up to an unknown arena of competition wherein the best survives. This phase which includes patterns of international pressure and negotiations along with the force of globalization and development based on western standards are the avenue towards globalization.

Many international institutions take over from the state's prerogatives, in almost all cases with their consent and they have the right to judge and to coerce what the states make on their own territory even to exercise jurisdiction and control over national issues ${ }^{5}$.

The preceding effects to globalization targets states that remains outside the garb of globalization by using multiple instruments that assist this transition. For instance, in the communist- influenced states post the cold war, there was a transition using the 'shock therapy' which based socio-eco-political factor to shift the status quo to an open and progressive economy and society. This change in the status quo happened in the backdrop of the disintegration of the former Union of Soviet Socialist Republic (USSR) driven by socialist-communist ideologue, thus creating new international alignments, thereby causing a transition in the philosophy of these USSR-influenced states to an open marketed environment. This transition however is not a standardized way of switching. In contrast to this, People's Republic of China, opened as an independent decision of internal and domestic reform, after a long history of protectionist and closed market economy.

Globalization as internationalization. This notion treats globalization in a narrow sense as an increase in cross-border relations among organizations, that is, identities and communities that extend beyond national jurisdictional boundaries. This is nothing new: international trade and other aspects of economic and political relations began to grow among nations centuries ago. The field of international relations is an outgrowth of such a development.

"The internationalization of public administration is not new either, though it gained momentum after World War II, when both the United States and the Soviet Union internationalized their satellite nations and, in turn, the ways in which public administration was thought about and practiced. The rise of the United Nations and its affiliate agencies also promoted internationalization."

Such a perspective as shown above puts internationalization in a position of a lens merely to revisit and view globalization, it however fails to recognize the fact that, internationalization is a pre-

\footnotetext{
${ }^{3}$ Hirst, P., Thompson, G., Globalizarea sub semnul întrebarii, Bucuresti: Ed. Trei, 2002, p. 361;

${ }^{4}$ Huntington, S., Ciocnirea civilizatiilor si refacerea ordinii globale, Ed. Antet, 1998, p. 187-189

${ }^{5}$ Public Administration and GlobalisationSORIN PUREC

${ }^{6}$ The birth and growth of the Comparative Administration Group (CAG) was the outcome of this development (Waldo, 1980; Riggs, 1998)
} 
condition rather than a lens, which forms the ground work or the foundation for a huge globalized world.

\section{ALPHA-STATE-THEORY OF INTERNATIONALIZATION}

To see how internationalization switches status-quo by influencing philosophy of politics and social fabric of the nation-state, it becomes essential to understand the principles by which the nation state is governed. However, to generalize a theoretical assumption, is to understand what a realist perspective towards nation-state is. As implicit to the realist perspective, the international arena is in a state of anarchy with absence of any central regulatory governing authoritative body.

Being said that, the states, in an anarchical environment compete for survival. Survival here calls for promoting national interest and states acting as individuals with self-interest, thus any state, no matter how diverse it may be, will always stand by promoting national interests first.

Promotion of national interest can't be equitable because as per the principles of economics; the resources are scarce and limited. Therefore, this imbalance causes a power struggle and changes in balance of power in the international arena.

With a normative perspective, we thereafter see a power struggle and security dilemma, but the fundamentals remain in the realist principle of 'survival'.

Therefore, the wide-scale acceptance of globalization around the world subtly must hint to the fact that greater inter-dependence decreases risks as well as increases chances of survival.

Thus, internationalization as a change in the status-quo guarantees advantages to the philosophicalpolitical narrative of contemporary nation-states. Acting as the avenue towards the cobweb-model of world politics and increased perks of globalization.

The progression of internationalization as a standard model based on generic assumptions of the third world can be clearly seen in the Alpha-State-Theory of internationalization.

With these as pretext to the Alpha-State-Theory of internationalization;

\subsection{Case of Relative Protectionist Democracies (Rpds)}

We assume a democratic protectionist state, with a narrative of protecting domestic industries and small- scale enterprises called, alpha-state. Citizens of alpha-state are in perfect knowledge of the developments in the outside world. As a result of their exploitative past or any other reason, the economic developments in alpha-state remain relatively low.

Human nature directs to comparison and resentment; thus, the citizens of the alpha state grow frustrated and restless with their relatively low standards of living in comparison to the world outside.

Thereby, creating popular pressure on the democratic government. Perks of democracy; the party in power would do anything in order to remain in power, thus the immediate action of the government will to be, to cater to the demands of the people.

Here, increasing economic productivity, and thereby standards of living is a structural reform which will take time, keeping in mind the current narrative of the state (Of Protectionism).

However, changing the philosophical narrative of the state and bringing about an economic turnaround is a relatively more provocative solution. Here, the citizens will have a trade-off to make between the benefits of globalization in place of their current standard of living Vs. State's philosophical socio- political narrative of protectionism. Here, citizens behave as a unilateral rational being and will take actions to have a better life due to their perfect knowledge and rationality.

Seeing the political gains, the popular support and the international pressure. Alpha-state compromises upon its narrative and changes its directive towards more openness. Thereby creating a way for actual forces of globalization to act and thus, globalization to occur.

The phase of realization till the phase of bringing about administrative and executive changes to inculcate forces of globalization is where internationalization rests as a means to the end of globalization.

Considering, internationalization remains a non-binary concept, a model representing it must also 
cater to as many cases as possible, thus;

\subsection{Case of Economic Jeopardy (EcoJ)}

In the next case the assumptions remain the same, however alpha state starts to face an economic slowdown within itself primarily due its current narrative of protectionism. This escalates into an economic crisis causing alpha state to finally open-up as a bail-out mechanism, driven by various international narratives and transnational bodies of economic, social and cultural interests. The entire scenario from the start of the economic slowdown till the bail-out takes place is when internationalization becomes the means towards globalizing alpha state.

\subsection{Case of Realist International System (RIS)}

In another scenario, keeping the same assumptions in mind, alpha state faces international pressure to open-up its markets and adopt facets of globalization. This condition can easily arise because as per the assumptions; international system remains an anarchy and states fight for survival and selfinterest. Here self-interest of one state may result in pressure on another state which in this case remains alpha-state.

Thus, while international pressure is for self-interest, alpha-state will have to open up because the primary objective by which states stand by in the international arena is survival.

The phase from the creation of pressure till alpha state finally acts, is internationalization being a means towards globalization.

\subsection{Case of Politically Fragile States and Situations (PFFS)}

In case of a fragile domestic situation because of any socio-political reason which may cause political instability within alpha state. The narrative of protectionism will take a back-seat and due to the instability and anarchy, the international arena will take advantage of this by making sure that alpha state opens up and thereby gets exploited due to the absence of a strong and stable government.

\subsection{Case of Perfect Protectionism and Surplus (PPS)}

In opposition to these cases stands a case which closely resembles the study of People's Republic of China, wherein alpha-state achieves considerable economic growth and productivity causing surplus produce and gains. In such a case alpha state, will keep the self-interest before its old narrative of protectionism and will open up so that it can bear fruit from the economic surplus the domestic industries generate.

Thus, the alpha-state theory does not act as a restrictive ideologue limiting the nature of globalization. However, highlights the trade-off between essentials on managing socio-political and economic life and a generic state narrative. Showcasing the phases on internationalization which finally creates conditions for the forces of globalization to act and thus, resulting in a state to adopt, selectively the facets of globalization in diverse schemes.

\section{Historical Validation of the Alpha State Theory}

In summation of the Alpha state theory, the essence of the text remains not marginally in principle, but facets of the entire theory are derivatives from learnings of history. This section of the paper briefly considers one case study each that closely resembles all the five cases of the Alpha State Theory, thereby providing a historical narrative and backing to the alpha state theory.

To look at it with a historical lens is to also consider the understanding that the alpha state theory is a distinct narrative to the globalization in the Third World States. It aims to bridge the gap between a Pre-Globalizing society and globalizing or globalized society, essentially calling the bridge 'Internationalization'.

Being, said that, the paper considers the following cases to draw forth a more historic backing to the theory.

The case of Perfect Protectionist Democracies can be juxtaposed with the historical meltdown of the former USSR. At first it may seem widely in contrast to using USSR in explaining the case of perfect protectionist democracies, under the scheme of the alpha state theory. However, on a closer examination, the case of PPDs goes hand in hand with the collapse of USSR. 
"Explaining the collapse of the Soviet system is different to explaining the causes of perestroika. The causes of perestroika are generally agreed upon: reform was initiated because of economic decline, Soviet loss of international power relative to Cold War rivals, the accumulation of social problems, and the need for political reform to deal with some, if not all, of these problems. Explanations of Soviet collapse all recognize the range of problems that the USSR faced in the mid-1980s and that led to perestroika."7

This paper, highlights the perspective quoted above. For, the PPD Case begins with economic decline, which perhaps was the main cause of Perestroika, in the USSR, this economic decline was thereafter coupled with the realization of loss of international power, relative to that in other western liberal states. And the relative backwardness in terms of socio-economic as well as political life. This aspect closely works in conjunction with the case of PPD, where people grow frustrated due to lack of socioeconomic boom.

This frustration can have dual outcomes, one includes timely resolution of the demands which further contributes in satisfying the needs and wants of people. This ideally is the case in the Systems Theory given by David Easton, where the political system acts as a mechanism of inputs and outputs, processed by a political system, that stays central to the model.

Usually this is more practically observed in democratic states, which is why in the case of PPDs, the resolution of public demand and wants is manifested as an economic-democratic reform that emerged as an outcome of people's participation.

The other case is the case of disintegration of the USSR, wherein, due to demands not being heard at the right time, from the right people the state collapses.

The commonality in both the cases that of USSR or PPDs is that eventually the bi-products are opened- up, relatively liberalized states. Thus the case of PPDs holds its derivative in the collapse of USSR, even though USSR was never a democracy.

The case of economic jeopardy is the most typical case of internationalization and its forces acting upon protectionist states, the case of EcoJ can be compared directly with the case of the Republic Of India and its Liberalization, Globalization and Privatization (LPG) reforms.

"Among developing countries, India's growth experience during the past five decades has been unique. Unlike many of its East and Southeast Asian neighbors, India did not grow at "miracle" rates that exceeded 6 percent and reached as high as 10 percent. Nor, unlike Africa and Latin America, did it suffer periods of prolonged stagnation or decline. For three of the five decades (1950-80), India's economy grew steadily at the so-called Hindu rate of $31 / 2$ percent a year in real terms, and during the next two decades it grew at annual rates between 5 and 6 percent. Although the credit for this steady growth without prolonged stagnation or decline goes to the macroeconomic stability and policy credibility that the government provided, the blame for the relatively low rate of growth, especially during 1950-80, must be assigned to the myriad microeconomic distortions and heavy state intervention that straitjacketed India's entrepreneurs. The government effectively stamped out domestic competition through strict investment licensing and eliminated foreign competition through strict import licensing.

It was only during the second half of the 1980s that the government began to loosen its grip on investment and import licensing; this was followed by a more systematic and comprehensive opening up in the 1990s and after."

As clearly depicted India picked a strict path of protectionism post 1947, and managed a steady growth rate, however, in the due course of time a Balance of payment along with a foreign exchange crisis developed causing an overall economic crisis, and massive criticism to its public sector undertakings primarily due to its protectionist policies.

"Currently, the Indian economy is passing through a severe crisis which is due to an accumulation of

${ }^{7}$ (see Robinson, 2018, chapter 3) Explaining Soviet collapse Neil Robinson Department of Politics and Public Administration, University of Limerick, Limerick

${ }^{8}$ ARVIND PANAGARIYA's Columbia University India's Trade Reform 
the combined effect of various forces operating in the domestic as well as the global economy.""

These lines perhaps are from a pioneering Indian scholar written during the economic crisis, the same paper further examines principally leftist policies and protectionism as a contributor to the current crisis As the crisis worsened with time, the Indian Government was perhaps left with only one alternative, being the LPG reforms.

However the EcoJ Cases do not end merely with administrative reformations however, it's more concerned with the way and conditions with which the reforms come about.

In almost all EcoJ cases wherein states face internal economic issues, they approach international financial institutions for loans or funds, now the conditions against these loans are extreme, papers from Indian scholars highlight, "IMF loan imply a substantial loss of freedom for the country with regard to its socio-economic policy formulation deserves to be examined carefully. "During the last couple of years, detailed country-wise studies have been made by the IMF itself to evaluate the experience of applying standard stabilization packages to a wide range of less developed countries. These studies have revealed many shortcomings of the basic IMF approach of imposing a uniform set of conditionalities." 10

"Since the early 'eighties, and following India's availing of SDR $5 \mathrm{bn}$. loan from the IMF, the process of relaxation of the regulatory system was pursued to give greater freedom to the private sector."

Hereon, the only bailout mechanism for the country was to accept the Washington Consensus, post which the LPG Reforms were adopted, now the central premise of the EcoJ case remains the intent and narrative of the Washington Plan, which was essentially seen as a bailout mechanism in return of massive central policy changes in a rather autocratic way to suit the needs of the global North.

"The process of adoption of planning and the decision for its liquidation followed differing routes. In sharp contrast to the process of evolution that the Indian development policy went through, especially during the initial years, announcement of the new economic policy package in 1991 had a large element of surprise for everyone. The new policies were adopted without discussion in public, Parliament, the ruling political party or the press" $" 12$

"The policy frame was delivered swiftly in order to quickly complete the process of changeover so as not to permit consolidation of any likely opposition to the implementation of the new policies. The strategy was to administer 'shock therapy' to the economy" ${ }^{\prime 3}$

"The policy package had been in use for many years in a number of Latin American and African countries and had been known by differing connotations such as 'Washington Consensus', 'Structural Adjustment Programme' and liberalization, in India it was projected as an indigenous and homegrown product." 14 "Lack of critical debate on the issue and yielding of no space for honest disagreement led to the emergence of a conformist culture in administration, politics, media and worst of all in academics." $" 15$

Many thus see the coming in of LPG reforms as a western instrument of exploitation. Because, the opening up of India's markets happened keeping centrally in mind the interests of international institutions, based on western philosophy of liberalization along with the lack of its democratic implementation, all of it together makes it a fundamental case of Economic Jeopardy within the alpha state theory.

The case of India falls under the EcoJ paradigm of the Alpha-State Theory however, it should not act as a limiting factor, so to say, that the case of India here, is just an instance of economic crisis or

\footnotetext{
${ }^{9}$ India's Economic Crisis: Nature and Remedies Bakul H Dholakia

${ }^{10}$ India's Economic Crisis: Nature and Remedies Bakul H Dholakia

${ }^{11}$ Washington Consensus and India-- Experience of the Last Decade S.K. Goyal \& K.S. Chalapati Rao

${ }^{12}$ Washington Consensus and India-- Experience of the Last DecadeS.K. Goyal \& K.S.

${ }^{13}$ The strategy was suggested by the World Bank. The Bank said: “... there is an interaction between the slowness of the reform and the final outcome, since a slow reform allows vested interests adversely affected by continued policy reforms to mobilize increasing support and halt the Contd...

${ }^{14}$ Sukumar Muralidharan, "Winning economists, influencing people", Frontline, April 9, 1993. See also "Backroom boys", Economic Times, March 8, 1993.

${ }^{15}$ Washington Consensus and India-- Experience of the Last Decade S.K. Goyal \& K.S. Chalapati Rao
}

$\begin{array}{lr}\text { International Journal of Political Science (IJPS) } & \text { Page| } 66\end{array}$ 
slowdown followed by gradual opening up of the state.

The understanding here being that the causes, effects or variations of an economic crisis or slowdown may be different and specific depending from case to case basis however, one simple commonality being the reason for opening up of the economy remains an internal failure of protectionist narrative or policies causing economic crisis or slowdowns. This understanding forms the pretext and the fundamental of EcoJ cases under Alpha-State Theory.

The cases of Realist International System serve more as a psychological understanding that works in the background within the structural or policy reforms of any state. Thus, RIS cases are ever prevalent in any historical record of states, opening up or globalizing because the spirit of survival is central to any state before anything else.

The cases of Politically Fragile States or PFSs, can be historically validated by briefly looking at the states that were formed after the disintegration of USSR, in most of which, initially an autocratic rule came, followed by a lot of political instability. This worked in advantage of western states to impose their narrative of liberalization on them. For instance, transition in Kazakhstan and Russia included massive privatization of public sector undertakings, many scholars even call it 'Garage Sale' where these government run industries were given out at throw-away prices.

The system of rapid, planned decentralization by international institutions, fueled by the ideologue of liberalization, that happened in these states after the disintegration can be attributed to the political fragility or the lack of democratically strengthened institutions.

Whereby, all states that came as a bi product of the disintegration were either completely new or under massive influence of USSR (Which had just collapsed). Thus, political fragility played a rather essential role in the opening up of these states.

"The case of perfect protectionism and surplus is derived from the economical success of the People's Republic of China, briefly analyzed, China since 1949, has undergone a shift from a largely agrarian society to an industrial powerhouse." ${ }^{\prime 16}$ In the process it has seen sharp increases in productivity and wages that have allowed China to become the world's second-largest economy.

The first two decades, China followed the policy of protectionism and worked on its domestic industrial base, marking substantial periods of growth in per-capita income and GDP.

"The authors of the NBER paper suggest this represented the success of the First Five-Year Plan, during which "6000 Soviet advisers helped establish and operate the 156 large-scale capital-intensive Soviet-assisted projects", significantly increasing the pace and quality (productivity) of industrialization in the country. However, it was followed by the Great Leap Forward (1958-1962), which undid many of the gains through worsening of incentives by banning material incentives and restricting markets." 17

These reforms, on their failure were then restricted, thus, leading to another period of productivity and per capita GDP growth

According to NBER authors, the Third Plenary Session of the 11th Central Committee of the Communist Party in December 1978 was the defining moment in shifting the country from its unsteady early economic trajectory on to a more sustainable path.

"Followed by the Law on Chinese Foreign Equity Joint Ventures being introduced, allowing foreign capital to China helping boost regional businesses although it took a while for the government to gradually ease pricing restrictions and allow companies to retain profits and set up their own wage structures." ${ }^{\prime 18}$ The essential observation here is the fact that China's policies were centrally planned by the Chinese government itself. All this not only helped to boost GDP from an annual average of $6 \%$ between 1953-1978 to $9.4 \%$ between 1978-2012 but also increased the pace of urbanization as workers were drawn from the countryside into higher-paying jobs in cities.

\footnotetext{
${ }^{16}$ weforum.org/agenda/2015/07/brief-history-of-china-economic-growth

${ }^{17}$ The Economy of People's Republic of China from 1953 Anton Cheremukhin, Mikhail Golosov, Sergei Guriev, Aleh Tsyvinski NBER Working Paper No. 21397 Issued in July 2015

${ }^{18}$ NBER Working Paper no. 21397
} 
This process of controlled evolutionary market liberalization led to the establishment of China as a major global exporter. It eventually allowed for the reopening of the Shanghai stock exchange in December 1990 for the first time in over 40 years and, ultimately, to China's accession to the World Trade Organization, as the second largest economy of the world.

Thus highlighting and validating the PPSs case of Alpha-State theory, so to say a controlled market liberalization that is free of external influence or pressures happen to become the second largest economy in the world, only opening up its markets according to its own policies in presence of a relatively strong economic foundation that was built behind the garb of its initial protectionist phase.

In totality a historical validation may not be perfectly accurate in terms of validation and credibility but solely serves the purpose of providing a rationale to the theory, precisely why the historical accounts of various states is not comprehensively elaborated. The purpose of this validation is also not to limit or factorize the scope of various cases under the Alpha-State theory but is to give a reference point towards it.

\section{FACETS AdMinistering THE AlPHa State THEORY}

This section briefly touches upon a few major facets that administer the working of the Alpha State theory, it becomes necessary to understand these facets to holistically look at the Theory.

The idea is governed by the fact that the narrative of alpha state opening up is either because of the selfish human nature or exploitation.

Giving it a micro-level analysis, states are a collective of micro actors, thus are governed by the very same virtues and values. In other words, states are made up of people, thus, they think and act like people.

The exploitative nature of states, creates the conditions of working for the alpha state theory, for example in the cases of EcoJ and PFSs, the shock therapy becomes an exploitative measure that somewhere emerges due to the selfish nature of humans. Thus, rather than creating compassionate bailout mechanism, international arena is governed by bailout policies based on exploitation and monetary returns.

Other facets of the alpha state theory comprise up of knowledge and soft influence, wherein the natural tendencies of humans to compare and have a relative judgment comes to play, many a times frustration grows and reforms are brought about only because people of the alpha state start comparing their state and standards with those of other which may be more prosperous. Thus, instincts of comparison pave the way forward for the alpha state to open up, conditions of soft influence also play a major role in this regard. More the soft influence, more the comparison and faster the reforms. Here, soft influence can be anything ranging from what the people of the alpha state think, believe or feel about themselves or about other states in the international arena, it may erupt from sources like popular culture, media, individual experiences etc.

The next facet perhaps the most fundamental is 'need'. States in the cases of EcoJ perspective gradually give in to the biased reforms only because the need to survive is prioritized over having justified and unbiased reforms. Simply put, states can only fight injustice, if they survive in the international arena.

Other states outside the EcoJ case also open up considering the need to do it, this need may be of multiple types including the need to increase market diversity, need to increase returns or foreign exchange, or even the need to bail out of a financial crisis, the list goes on and is never ending.

State egoism and competition also contributes to the working of alpha state theory, so to say, the desire of domination and power based on realist paradigm drives states to increase influence by whatever means suitable, this in contemporary times majorly refers to economic influence, which further then gives rise to the alpha-state theory.

This section, rather highlights the beauty of grey in social sciences, whereby there maybe end number of human attributes that contribute to the working of this theory however, only a few have been noted.

Similar to all observations above, these facets are not exhaustive and are just a part of an entire plethora of facets that make this theory. 


\section{CONCLUSION}

The scarcity of a theoretical perspective of the Third-world in regard to globalization remains apparent. Such a perspective is developed by understanding the rationale behind globalization and how it slowly unfolds as a result of internationalization.

The Alpha State theory becomes a starting point to developing such a paradigm by laying out practical historically validated cases of distinct states opening up and moving towards the path of globalization.

This theory becomes the starting point and the theoretical voice of states that have chosen the path of globalization and have somewhere been exploited. It further shows internationalization as a bridge between protectionist states and globalized or globalizing states. As per the theory, this bridge can be made using exploitative methods, political instability, economic need, domestic economic surplus or by the mere will of the states to survive in an anarchical international arena.

The theory comes from historic derivatives and various state related micro factors that have been mentioned earlier, providing a holistic ideologue towards the Third World perspective on globalization.

However, as mentioned, the theory serves as the starting point and calls forth towards more substantive and comprehensive research into the Third world perspective on globalization.

\section{REFERENCES}

[1] Journal of international business study, (THE INTERNATIONALIZATION PROCESS OF THE FIRM-A MODEL OF KNOWLEDGE DEVELOPMENT AND INCREASING FOREIGN MARKET COMMITMENTS JAN JOHANSON*

[2] Center of International Business Studies University of Uppsala JAN-ERIK VAHLNE* Institute of International Business Stockholm School of Economics)

[3] As Stephen Turner's Chapter on "Theory Development," Public Administration and Globalization SORIN PUREC

[4] Explaining Soviet collapse, Neil Robinson Department of Politics and Public Administration, University of Limerick, Limerick

[5] radjenovicsasa.wordpress.com/2013/09/09/three-phases-of-globalization/

[6] ARVIND PANAGARIYA's Columbia University India's Trade Reform India's Economic Crisis: Nature and Remedies Bakul H Dholakia

[7] Washington Consensus and India-- Experience of the Last DecadeS.K. Goyal \& K.S. Chalapati Rao Sukumar Muralidharan, "Winning economists, influencing people", Frontline, April 9, 1993.

[8] "Backroom boys", Economic Times, March 8, 1993. https://www.weforum.org/agenda/2015/07/briefhistory-of-china-economic-growth/

[9] The Economy of People's Republic of China from 1953 Anton Cheremukhin, Mikhail Golosov, Sergei Guriev, Aleh Tsyvinski NBER Working Paper No. 21397 Issued in July 2015

Citation: Vardaan Shekhawat. "The Alpha State Theory Internationalization as Means to the End of Globalization” International Journal of Political Science (IJPS), vol 5, no.3, 2019, pp. 60-69. doi: http://dx.doi. org/10.20431/2454-9452.0503005.

Copyright: (C) 2019 Authors. This is an open-access article distributed under the terms of the Creative Commons Attribution License, which permits unrestricted use, distribution, and reproduction in any medium, provided the original author and source are credited. 